\title{
A systematic decision support system to objectively evaluate retrospective energy efficiency modelling options
}

\author{
L.A. Botes ${ }^{1 \star}$, W. Booysen ${ }^{2}$, M.J. Mathews ${ }^{3}$, M. Kleingeld ${ }^{4}$ \\ Centre for Research and Continued Engineering Development, North-West University; consultants to TEMM \\ International (Pty) Ltd, P.O. Box 11207, Silver Lakes 0054, South Africa \\ 1. https://orcid.org/0000-0003-3194-7224 \\ 2. https://orcid.org/0000-0002-3922-5376 \\ 3. https://orcid.org/0000-0003-4439-8797 \\ 4. https://orcid.org/0000-0003-4435-6036
}

\begin{abstract}
Tax incentives are one of the methods used by the South African government to incentivise energy efficiency. One of these incentives is Section 12L of the Income Tax Act (1962), which allows a significant tax deduction as a result of quantifiable energy efficiency (EE) savings. The associated EE savings are calculated by means of baseline models and must be in accordance with the national standard for measurement and verification, i.e. SANS 50010, which is based on international practice. The present study developed a methodology that assists EE projects with incentive applications to objectively evaluate potential modelling options and ultimately select a final model. This methodology is based on the weighted sum method. It is verified by applying it to three actual case studies and is further validated by comparing the results obtained from the case studies to independent results of formal and successful incentive applications. The methodology allows for a transparent selection of a modelling option that is compliant with the relevant tax incentive regulatory requirements and untainted by personal bias.
\end{abstract}

Keywords: tax incentives; baseline models; transparent; measurement and verification

Journal of Energy in Southern Africa 30(2): 52-63

DOI: https://dx.doi.org/10.17159/2413-3051/2019/v30i2a5740

Published by the Energy Research Centre, University of Cape Town ISSN: 2413-3051

This work is licensed under a Creative Commons Attribution-ShareAlike 4.0 International Licence https://journals.assaf.org.za/jesa

Sponsored by the Department of Science and Technology

Corresponding author: +27 (0)101 407 835:

email: leeannbotes1@gmail.com 


\section{Introduction}

South Africa is actively driving energy efficiency, especially in the industrial sector, which is the largest national energy consumer (Department of Energy, 2010). One of the implemented initiatives is a tax incentive referred to as Section 12L of the Income Tax Act (Bergh, 2012; Morrow, et al., 2013; Schutte, 2013). This incentive gives applicants ZAR $0.95 / \mathrm{kWh}$ tax deduction for quantified energy efficiency (EE) savings. The high value of this incentive has driven significant development in measurement and verification $(\mathrm{M} \& \mathrm{~V})$ methods and techniques (National Treasury, 2013; SABS, 2017).The quantification of Section 12L energy savings is done in accordance with the South African National Standard (SANS) 50010 (SABS, 2017), which is based on industry leading guidelines such as the International Performance Measurement and Verification Protocol (IPMVP) and the Federal Energy Management Program (Efficiency Valuation Organisation, 2012; Grobler, 2010; U.S. Department of Energy, 2008). The strong link between the SANS 50010 and international $\mathrm{M} \& \mathrm{~V}$ practices makes the developed Section 12L-related techniques beneficial to the wider $\mathrm{M} \& \mathrm{~V}$ industry. The concept of Section $12 \mathrm{~L}$ is that the more qualifying, quantifiable energy is saved, the less tax is paid (Du Toit, 2011). It stipulates that a tax deduction allowance is awarded to tax payers for quantified EE savings (ZAR per verified $\mathrm{kWh}$ of EE savings) (Republic of South Africa, 2013). Since March 2015, this allowance was increased from ZAR $0.45 / \mathrm{kWh}$ of EE savings to ZAR $0.95 / \mathrm{kWh}$ (Republic of South Africa, 2015). This is the flagship incentive to overcome the financial barriers associated with the implementation of such $\mathrm{EE}$ initiatives (EEIs) and encourage energy-efficient operations (Botes, 2017). There are, however, apparently a number of challenges to overcome ( $\mathrm{Du}$ Toit, 2011), given that in 2016 only 14 Section 12L certificates were successfully issued out of a total 108 registered applications (SANEDI, 2016). A key challenge is to accurately calculate and verify the achieved energy savings, while adhering to the strict rules and regulations, as stated in the Section 12L Regulations (Booysen, 2014; Hamer et al., 2017; National Treasury, 2013). This challenge is a significant concern, as the calculated EE savings directly impact the Section 12L tax allowance certificate value (Booysen, 2014; Hamer et al., 2017). With the aim of mitigating the concerns and challenges associated with the incentive, various $M \& V$ practices are mandatory and stipulated in the Section $12 \mathrm{~L}$ regulatory structure. One such measure is the requirement that the quantified $\mathrm{EE}$ savings must be verified by an independent $M \& V$ body accredited by the South African National Accreditation System (SANAS) (Campbell et al., 2017; GreenCape, 2015;
Hamer et al., 2017; National Treasury, 2013). Furthermore, the $\mathrm{M} \& \mathrm{~V}$ process is required to be traceable, accurate and transparent, to ensure the protection of all stakeholders involved (Campbell, 2016; Hamer et al., 2017). The $M \& V$ practice thus forms a crucial part in the practical application of Section $12 \mathrm{~L}$ and will therefore be discussed in the next section. The key technical aspects relating to Section $12 \mathrm{~L} \mathrm{M} \& \mathrm{~V}$ can be evaluated by first identifying the basic M\&V approach as stated in the IPMVP (Figure 1 column 1 ). The appointed $\mathrm{M} \& \mathrm{~V}$ inspection body investigating the Section 12L potential of a certain EEI will essentially be involved with steps 1 , 2, 4, 5, 7 and 8 of the $M \& V$ approach (Janse van Rensburg, 2015). Each of the identified steps in the $\mathrm{M} \& \mathrm{~V}$ process is connected to a section in the SANS 50010 framework (Figure 1 column 2). These connections could be further summarised to identify the three key technical aspects of Section 12L on the right of Figure 1 : the selection of a measurement boundary, assessment of the baseline dataset and the development and evaluation of the baseline model. Each of these will be discussed in this section.

The EE savings may be determined for different measurement boundaries on a facility. This includes evaluating either a portion of the facility or the entire facility to assess the EE savings. Various methodologies are available in literature to identify and evaluate the feasibility of measurement boundaries (Booysen, 2014; Efficiency Valuation Organisation, 2012; Hamer, et al., 2017; Janse van Rensburg, 2015; SABS, 2017). Once a measurement boundary has been established, an accurate dataset must be compiled. According to SANS 50010, the dataset may consist of either all the parameters associated with the energy system, or only the significant governing parameters. However, an important factor that must be considered is the compliance of the dataset with the Section 12L Regulations. This becomes crucial when considering that industrial systems usually have large amounts of data sources and measurement points available, all with different levels of accuracy and compliance. The dataset options should, therefore, be evaluated (Hamer et al., 2017). Existing and well-established methodologies from literature can readily be used in this study to evaluate the baseline dataset (Gous et al., 2016; Hamer et al., 2017; SABS, 2017).

The EE savings are calculated via an EE model after selecting a measurement boundary and dataset. Different mathematical methods may be used for the quantification of the $\mathrm{EE}$ savings. These include energy intensity calculation, simulation, predictive modelling and various regression methods (Hamer et al., 2017). Previous studies recommended the development of multiple models to quan- 


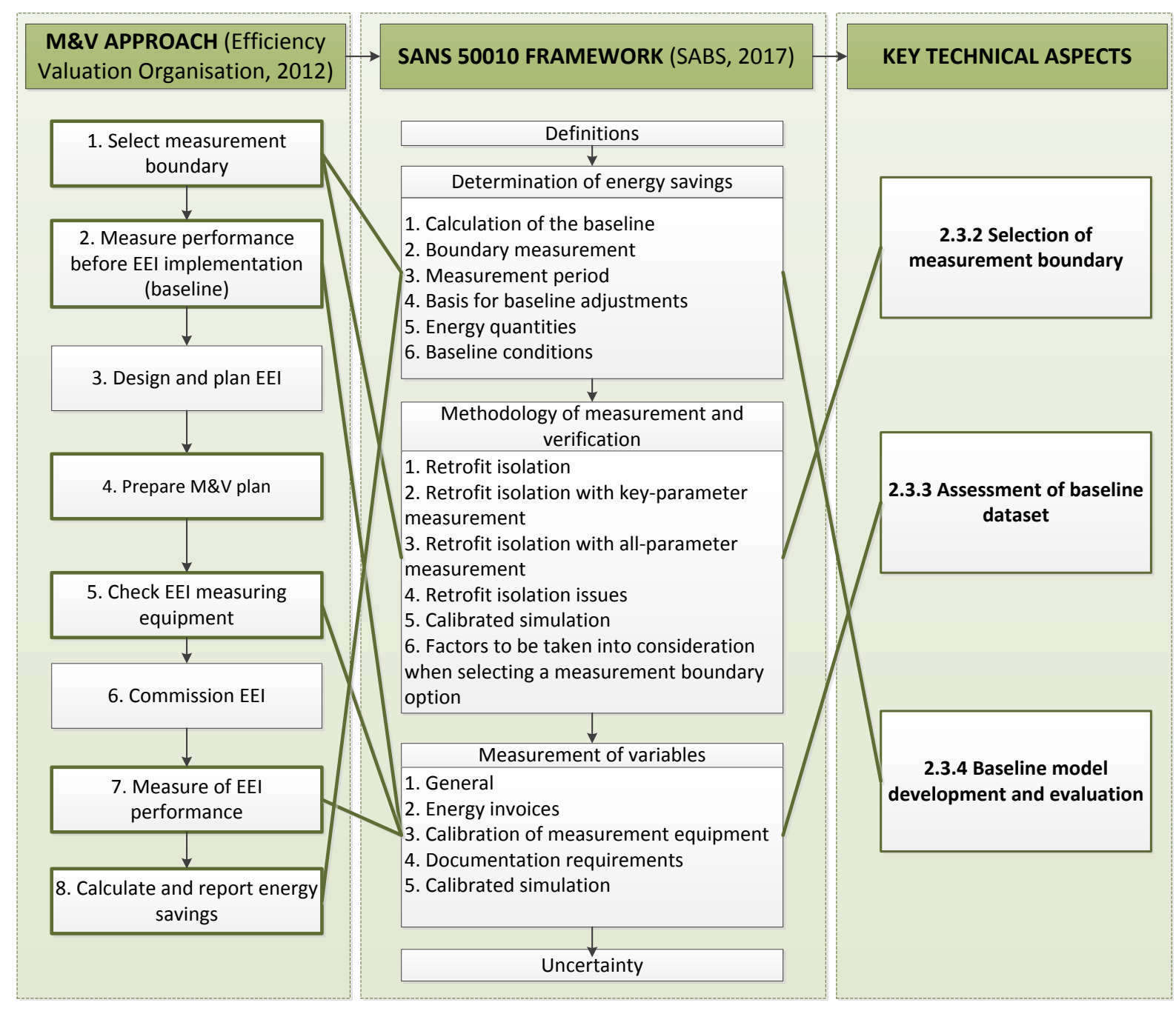

Figure 1: Key technical aspects of Section 12L. Source: Botes (2017)

tify the EE savings (Campbell, 2016; Hamer et al., 2017). Each of the developed models varies according to their selected measurement boundaries, datasets and calculation methods.

Numerous baseline modelling options are available when considering the various options of measurement boundaries, datasets, and calculation methods. Well-established methodologies regarding each of these three key technical aspects of Section 12L M\&V are available in literature and can readily be used in this study (Gous et al., 2016; Hamer et al., 2017; Janse van Rensburg, 2015; SABS, 2017). The methodologies result, however, in numerous modelling options that may be considered when determining the achieved EE savings. There is no established method to aid in the selection process of the final model, which becomes vital considering the direct impact the chosen modelling option has on the monetary value associated with Section 12L. A need, therefore, exists to prove that the most appropriate model was chosen. The various models should be evaluated to ensure that the final model adheres to all the requirements associated with Section 12L. Furthermore, the evaluation process is required to be transparent to increase the confidence of the reported EE savings. Therefore, the objective of this paper is to develop a methodology that assists the Section $12 \mathrm{~L}$ application process to evaluate and select a final model for Section 12L applications when more than one modelling option is available.

Previous research and development work recommended that multiple boundaries and models be developed to holistically assess energy saving measures (Campbell, 2016; Hamer et al., 2017). The resulting assessments produced multiple potential results (and multiple potential tax benefits in the Section 12L context). These studies, however, do not give guidance on how to evaluate the potential modelling options. This becomes critical since the chosen model directly impacts the monetary value associated with Section 12L. These studies, however, do not give guidance on how to evaluate the potential modelling options. This becomes critical 
since the chosen model directly impacts the monetary value associated with Section 12L. The present study, therefore, focussed on the development of a systematic decision support system to objectively evaluate potential modelling options.

\section{Methodology}

\subsection{Decision support methods}

Making a decision based on multiple objectives is referred to as multi-criteria decision making (MCDM), which takes several conflicting, qualitative and/or quantitative criteria into account and results in a compromised solution that is acceptable to all stakeholders. Thus, in the MCDM process a solution between alternative options is obtained which best fits these criteria (Kolios et al., 2016). When addressing MCDM problems, a decision needs to be made between multiple alternatives that must adhere to various and often conflicting criteria. Thus, choosing a Section 12L model that adheres to multiple legal and technical requirements is a multi-criteria decision problem. A generic method of solving multi-criteria decision problems was therefore investigated from various literature (Azar, 2000; Bruen, 2008; Mateo, 2012; Tzeng et al., 2005; Volkart et al., 2017). The identified steps are to:

- generate/identify alternative solutions;

- establish criteria;

- evaluate alternatives;

- apply a multi-criteria decision aid (MCDA) method; and

- evaluate results and recommend a suitable solution.

These generic steps were used to select the best Section 12L model among multiple modelling options. The MCDA methods are existing numeric techniques aiding the decision-making process. They have been used extensively in various fields that include: resource allocation planning (Ogryczak, 2007); the medical field (Azar, 2000; Hancerliogullari et al., 2017); and most prevalently, the sustainable and renewable energy field (Kolios et al., 2016; Mateo, 2012). When applied to the energy field, the most common MCDA methods include: the weighted sum and weighted product method (WSM/WPM) (Carrico et al., 2014; Kolios et al., 2016; Mateo, 2012); technique for the order of preference by similarity to the ideal solution (TOPSIS) (Kolios et al., 2016; Mateo, 2012); analytical hierarchy process (AHP) (Kolios et al., 2016; Mateo, 2012; Saaty, 2008); élimination et choix traduisant la realité (ELECTRE) (Carrico et al., 2014; Kolios et al., 2016; Mateo, 2012); and the preference ranking organisation method for enrichment evaluation (PROMETHEE) (Kolios et al., 2016; Mateo, 2012).

The WSM is the simplest and most widely used method (Triantaphyllou, 2013). It is also straightforward to implement and transparent (Kolios et al.,
2016). The Section 12L M\&V results should be presented to various stakeholders and therefore needs to be transparent. The stakeholders might also not have the expertise to understand complex methods. The WSM was, therefore, the preferred method used throughout this study. Comparative studies have also shown similar results between the WSM and the more complex methods (Kolios \& Read, 2013; Kolios et al., 2016). The present study used WSM to evaluate multiple modelling options to quantify the associated EE savings and, ultimately, select a final modelling option. This was done by first establishing relevant model evaluation criteria. Secondly, weights were assigned to each criterion. In the third and final step, each alternative modelling option was assessed, and a multi-criteria score was determined for each modelling option. The modelling option with the highest multi-criteria score was considered as the preferred modelling option to quantify the associated EE savings.

\subsection{Selection of criteria}

In the first step, the relevant evaluation criteria were identified. Extensive research was done in various relevant fields to identify the criteria that Section 12L models need to adhere to. These research areas include, industrial energy efficiencies (Bergh, 2012; Hasanbeigi, et al., 2012; Morrow, et al., 2013; Schutte, 2013; Worrel \& Galitsky, 2005); Section 12L Regulations and Standard (Du Toit, 2011; National Treasury, 2013; Republic of South Africa, 2013; Republic of South Africa, 2015); industrial measurement and verification (Booysen, 2014; Campbell et al., 2017; Hamer et al., 2017; Janse Van Rensburg, 2015; SABS, 2017); and decision support methods (Bruen, 2008; Kolios et al., 2016; Mateo, 2012; Saaty, 2008). This produced the following list of evaluation criteria to assess Section 12L models:

- $\quad$ compliance of measurements $\left(\mathrm{C}_{1}\right)$;

- conservativeness of quantified $\mathrm{EE}$ savings $\left(\mathrm{C}_{2}\right)$;

- model correlation $\left(\mathrm{R}^{2}\right)\left(\mathrm{C}_{3}\right)$;

- root mean squared error of model (RMSE) $\left(\mathrm{C}_{4}\right)$;

- $\quad$ significance of quantified savings $\left(\mathrm{C}_{5}\right)$;

- variance in savings $\left(\mathrm{C}_{6}\right)$; and

- fraction of energy accounted for $\left(C_{7}\right)$;

The first two criteria consider key legal requirements of a Section 12L application. This includes the $\mathrm{C}_{1}$ used in the model development as well as $\mathrm{C}_{2}$. According to the standard, two data sources are deemed Section 12L compliant - data from invoices and measurements from calibrated equipment. The compliance of measurements is a requirement to ensure accuracy. The calibration of equipment must be done by SANAS-accredited calibration laboratories or specialists approved by the original equipment 
manufacturer (SABS, 2017). The Section 12L Regulations require the quantification of the $\mathrm{EE}$ savings to be done in accordance with the technical guidelines provided in the standard (National Treasury, 2013). These guidelines ensure that savings are quantified conservatively, which means that the reported savings should be the actual achieved savings or less (SABS, 2017). This ensures that any uncertainty relating to the quantified savings is mitigated. During the reviewing process of the application, the EE may thus be adjusted towards lower values to compensate for uncertainty. It is, therefore, critical to prove that the selected model is a conservative calculation of the achieved $\mathrm{EE}$ savings. Criteria 3 and 4 evaluate the model accuracy by considering the most common statistical parameters used to evaluate regression models. This was done since regression models are the most prevalent method of quantifying energy savings (Booysen, 2014; Campbell et al., 2017; Hamer et al., 2017). The most prevalent statistical parameters used include $\mathrm{C}_{3}$ and $\mathrm{C}_{4}$ (Booysen, 2014; Hamer, 2016) . The $\mathrm{C}_{3}$ is the primary indicator of the fit of a regression line and the relationship between the variables. The statistical relevance of $\mathrm{R}^{2}$ becomes stronger as it approaches 1 ; however, it is typically acceptable to have a value above 0.75 (Booysen, 2014; Campbell, 2016). The RMSE represents the error between the predicted values by the model and actual values. Typically, the RMSE should be below $15 \%$ (Booysen, 2014). The last three evaluation criteria include $C_{5}, C_{6}$ and $C_{7}$. Criterion $5\left(C_{5}\right)$ refers to the percentage of the EE savings relative to the baseline energy consumption. A higher significance of the quantified savings $\left(\mathrm{C}_{5}\right)$ is deemed an indication that the correct measurement boundary was isolated and that the results are not just because of process noise. Extreme models are identified by considering the variance in savings $\left(\mathrm{C}_{6}\right)$ of a specific model to the alternative modelling options. The last criterion is $\mathrm{C}_{7}$, which indicates that the largest and most relevant energy parameters with respect to the chosen boundary have been included in the model. These last three criteria evaluate the technical soundness of models.

The seven criteria identified in this section represent the criteria that Section 12L models should adhere to. Alternative modelling options will, therefore, be evaluated according to each of these criteria in this study. More detail on assessing each modelling option is given in Section 2.4.

\subsection{Weighting of criteria}

In the second step, the relative importance of each criterion was established by attaching numerical weights to each criterion. In this study, pairwise comparisons were used to determine the criteria weights, a process that was first introduced in 1980 and has become a preferred method (Eastman, 1999; Saaty, 2008). In this process, a reciprocal scale is used to rate each criterion for its importance relative to every other criterion. The reciprocal scale shown in Figure 2 is used to indicate how much a criteria is more important than the criteria it is compared to.

An $n \times n$ (for $n$ decision criteria) matrix of ratings is obtained when completing the pairwise comparisons. The diagonal of the matrix will be equal to 1 since the importance of a criterion relative to itself is equal. When comparing two criteria with each other, one automatically enters the reciprocal rating in the transpose comparison. The completion of the pairwise comparison matrix is followed by determining the criteria weights by raising the matrix to large powers, adding each row and dividing by the total sum of all the rows (Saaty, 2008). Since the weights of seven criteria need to be determined in this study, a $7 \times 7$ matrix is derived. A completed $7 \times 7$ pairwise comparison matrix is presented in Table 1.

A survey was used to obtain the criteria weights used in this study to test the applicability of the methodology. Ten people with experience in the field of $M \& V$ were asked to complete the pairwise comparison matrices. Their experience ranged between two and ten years, with an average of four, while their qualification ranged from Bachelor of Engineering to Doctor of Philosophy. Two have completed the Certified Measurement and Verification Professional programme. The respective weights obtained from the completed surveys are summa rised in Table 2. All the respective weights fall within three standard deviations of the mean (derived weight) value.

Intensity of importance

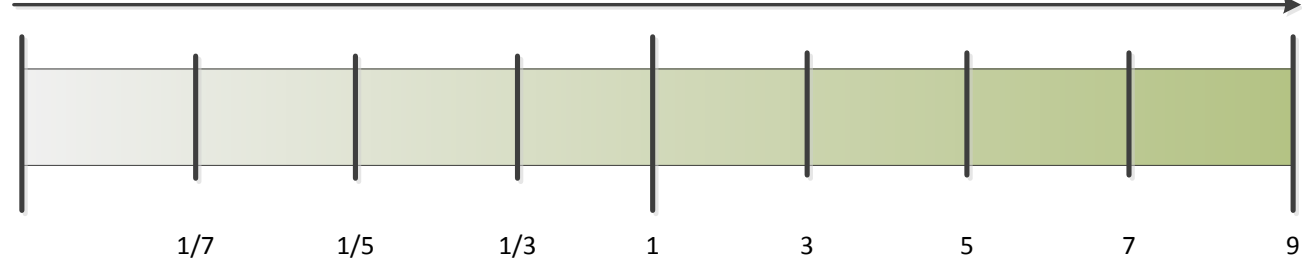

Figure 2: 9-point reciprocal scale used to indicate the importance of one criterion compared to another. 
Table 1: Pairwise comparison matrix for criteria weight determination.

\begin{tabular}{lccccccc}
\hline & Criterion & Criterion & Criterion & Criterion & Criterion & Criterion & Criterion \\
& 1 & 2 & 3 & 4 & 5 & 6 & 7 \\
\hline Criterion 1 & 1 & $1 / 3$ & 3 & 3 & 3 & 5 & 5 \\
Criterion 2 & 3 & 1 & 3 & 3 & 1 & 1 & 3 \\
Criterion 3 & $1 / 3$ & $1 / 3$ & 1 & 1 & $1 / 3$ & $1 / 3$ & $1 / 3$ \\
Criterion 4 & $1 / 3$ & $1 / 3$ & 1 & 1 & $1 / 5$ & $1 / 3$ & $1 / 3$ \\
Criterion 5 & $1 / 3$ & 1 & 3 & 5 & 1 & 1 & 1 \\
Criterion 6 & $1 / 5$ & 1 & 3 & 3 & 1 & 1 & 1 \\
Criterion 7 & $1 / 5$ & $1 / 3$ & 3 & 3 & 1 & 1 & 1 \\
\hline
\end{tabular}

Table 2: Derived criteria weights indicating the relative importance of each criterion.

\begin{tabular}{lcc}
\hline \multicolumn{1}{c}{ Criterion } & Derived weight & Standard deviation \\
\hline Compliance of measurements $\left(\mathrm{C}_{1}\right)$ & 0.21 & 0.06 \\
Conservativeness of savings $\left(\mathrm{C}_{2}\right)$ & 0.17 & 0.07 \\
$\mathrm{R}^{2}\left(\mathrm{C}_{3}\right)$ & 0.18 & 0.12 \\
$\mathrm{RMSE}\left(\mathrm{C}_{4}\right)$ & 0.11 & 0.07 \\
Significance of savings $\left(\mathrm{C}_{5}\right)$ & 0.13 & 0.10 \\
Variance of savings $\left(\mathrm{C}_{6}\right)$ & 0.11 & 0.06 \\
Fraction of energy accounted for $\left(\mathrm{C}_{7}\right)$ & 0.10 & 0.05 \\
\hline
\end{tabular}

The survey results showed reasonable consensus between the $\mathrm{M} \& \mathrm{~V}$ professionals for most criteria. This is considered acceptable to test the applicability of the methodology. However, improvement of the consensus could be obtained by increasing the sample size. More detail on how the established criteria weights are incorporated into the EE model assessment of this study is given in Section 2.4.

\subsection{Assessing model performance}

In the third and final step, each available modelling option was assessed according to each criterion. This was done by first assessing the performance of each model with respect to each criterion. The results were then summarised in a performance matrix, which consisted of different units depending on the evaluation criteria. The scores in the performance matrix were, therefore, normalised to eliminate the various units present and obtain comparable scores. A scale rating of $0-1$ was used to normalise the various units in this study. The scale was based on a relative strength of preference. For each criterion, a least and most preferred scenario was identified and attached to the anchor points of the scale ( 0 and 1$)$. The least and most preferred scenarios with respect to the seven criteria identified in this study are summarised in Table 3.

The least and most preferred scenario with respect to model compliance $\left(C_{1}\right)$ was either that no compliant measurements were used or that all the measurements used to develop the model were Section $12 \mathrm{~L}$ compliant. When considering the conservativeness of the quantified $\mathrm{EE}$ savings $\left(\mathrm{C}_{2}\right)$, the 0anchor point (least preferred scenario) was the least conservative $\mathrm{EE}$ savings between the various modelling options. This was equal to the highest $\mathrm{EE}$ savings value. The 1 -anchor point (most preferred scenario) was then the most conservative EE saving, i.e., the lowest savings value. The least preferred scenario would be a $\mathrm{R}^{2}$ value of 0 when considering the correlation of a model $\left(\mathrm{C}_{3}\right)$. This would indicate that no correlation existed between the variables used to develop the model. The most preferred correlation was a $R^{2}$ value of 1 , which is indicative of a good fit of the regression line and relationship between variables (Booysen, 2014; Campbell, 2016). Literature recommended that the RMSE $\left(\mathrm{C}_{4}\right)$ should typically be below 15\% (Booysen, 2014), therefore RMSE values of $15 \%$ or higher were considered the least preferred scenario. An RMSE of $0 \%$ was the most preferred scenario since this would indicate that there is no error between the predicted values by the regression model and the actual values. The least preferred scenario with respect to the significance of savings $\left(\mathrm{C}_{5}\right)$ was that there was no significance (significance of zero). The most preferred scenario was the significance of the quantified $\mathrm{EE}$ savings of the model with the highest significance of 
Table 3: Criteria normalisation scoring scale.

\begin{tabular}{|c|c|c|}
\hline \multirow[t]{2}{*}{ Scoring scale } & 0 & 1 \\
\hline & Least preferred & Most preferred \\
\hline $\begin{array}{l}\text { Compliance of measurement } \\
\left(\mathrm{C}_{1}\right)\end{array}$ & $\begin{array}{l}\text { No compliant measurements } \\
\text { used }\end{array}$ & $\begin{array}{l}\text { All measurements used are } \\
\text { compliant }\end{array}$ \\
\hline $\begin{array}{l}\text { Conservativeness of savings } \\
\left(\mathrm{C}_{2}\right)\end{array}$ & $\begin{array}{l}\text { Least conservative (highest } \\
\text { EE savings) }\end{array}$ & $\begin{array}{l}\text { Most conservative (lowest } \\
\text { EE savings) }\end{array}$ \\
\hline Correlation $\left(\mathrm{C}_{3}\right)$ & $\begin{array}{l}\text { No correlation between variables } \\
\text { ( } \mathrm{R}^{2} \text { of zero) }\end{array}$ & $\begin{array}{l}\text { Perfect correlation between } \\
\text { variables }\left(\mathrm{R}^{2} \text { of } 1\right)\end{array}$ \\
\hline $\mathrm{RMSE}\left(\mathrm{C}_{4}\right)$ & RMSE larger than $15 \%$ & RMSE of zero \\
\hline Significance of savings $\left(\mathrm{C}_{5}\right)$ & No significance (zero) & Maximum significance \\
\hline Variance in savings $\left(\mathrm{C}_{6}\right)$ & $\begin{array}{c}\text { Maximum distance from average } \\
\text { savings }\end{array}$ & No variance in savings (zero) \\
\hline $\begin{array}{l}\text { Fraction of energy accounted } \\
\text { for }\left(C_{7}\right)\end{array}$ & No energy accounted for (zero) & $\begin{array}{c}100 \% \text { of energy accounted } \\
\text { for }\end{array}$ \\
\hline
\end{tabular}

$\mathrm{RMSE}=$ Root mean squared error, $\mathrm{R}^{2}=$ model correlation, $\mathrm{EE}=$ energy efficiency

savings between the various modelling options. Models with large variances in savings $\left(\mathrm{C}_{6}\right)$ with respect to the average savings between multiple modelling options indicate extreme models. The least and most preferred scenarios with respect to this criterion were, therefore, the maximum variance from the average savings and no variance from the average savings, respectively. When considering the fraction of energy, a model accounts for $\left(\mathrm{C}_{7}\right)$ the least preferred scenario was that the model accounts for zero percent of the energy, while the most preferred scenario was that the model accounts for $100 \%$ of the energy within the selected measurement boundary of the model. By using the anchor points of each criterion, the performance scores could be linearly scaled to obtain a score value between 0 and 1 for each model with respect to each criterion. Thereafter, the weighted scores were calculated by multiplying each evaluation score with the respective criteria weight from Table 2, using Equation 1 (Triantaphyllou, 2013).

$$
\text { weighted score }=a_{i j} w_{j}
$$

where $a_{i}$ denotes the evaluation score (between 0 and 1) of model $i$ and $w_{j}$ the weight of criteria $j$. The overall score may also be referred to as the multicriteria score since it takes all the evaluation criteria into consideration. The WSM was used to calculate the multi-criteria scores and rank the results obtained. According to the WSM, the overall score of each alternative is equal to the sum of the respective weighted scores in terms of each criterion for that alternative, as in Equation 2 (Triantaphyllou, 2013).

$$
A_{i}=\sum_{j=1}^{n} a_{i j} w_{j}
$$

where $j=1,2, \ldots, n$ denotes the evaluation criteria. Furthermore, $a_{i j}$ denotes the evaluation score for alternative $i$ in terms of criteria $j$, and $w_{j}$ the weight of criteria $j$.

Scores were used to rank the alternative models to identify the least and most preferred modelling option the multi-criteria. The WSM identifies the optimum solution as the one satisfying Equation 3 (Triantaphyllou, 2013).

$$
A_{W S M}^{*}=\operatorname{Max} \sum_{j=1}^{n} a_{i j} w_{j}
$$

The multi-criteria scores were, thus, ranked from the highest to the lowest score. The model in first place (having the highest score) was recommended as the preferred model according to the WSM.

\subsection{Validation of model}

The results obtained from the methodology were validated by comparing the model recommended by the methodology to the model chosen by an independent SANAS-accredited M\&V inspection body. The selected models by the $\mathrm{M} \& \mathrm{~V}$ inspection body were also submitted as formal Section 12L applications and Section 12L certificates were issued for the applications.

\section{Results \\ 3.1 Results of case studies}

The methodology was applied to three case studies: A, B and C. Case study A consisted of steam stations. 
During the assessment period the water and coal quality to the steam stations were improved, which resulted in a measurable improvement in EE performance. Case study $B$ was focused on a relined blast furnace, which reduced heat loss and improved EE. Case study $\mathrm{C}$ was focused on the compressed air network of a gold mine. During the performance assessment, the compressor control philosophy was optimised to increase the EE of the compressed air network. For each of the case studies, well-established methodologies available in literature (as described in Section 1) were used to develop alternative modelling options to quantify the EE savings associated with the respective EEIs. The main variations between them were according to the selected measurement boundary, data and calculation method.

Case study A resulted in five different modelling options, of which the quantified savings ranged from 251.4 GWh to 341.2 GWh. Three different modelling options were developed for both case study B and case study $\mathrm{C}$. The EE savings resulting from the three modelling options varied between 234.2 GWh and 348.4 GWh for case study B, and between 6.2 GWh and 6.8 GWh for case study C.

The overall score of each model after evaluating the different models was determined and used to rank the models for each case study. Figure 3 summarises the overall scores of the different options used to model and quantify the EE. The results were ranked and numbered from 1 to 5 for case study $A$, and 1 to 3 for case studies $\mathrm{B}$ and $\mathrm{C}$. Figure 3 also presents the contribution of each criterion to the overall score of each model.

Figure 3 shows that for case study A, Model 2 and Model 3 obtained higher scores than the other three models presented because of being regression analyses. The other three models were based on intensity calculations and, therefore, did not obtain a score with respect to the correlation and RMSE evaluation criteria. A large portion of the score accredited to Model 3 was attributable to the conservative nature of the model. Model 3 obtained the largest overall score and is, therefore, recommended as the final Section 12L modelling option according to the methodology for case study A.

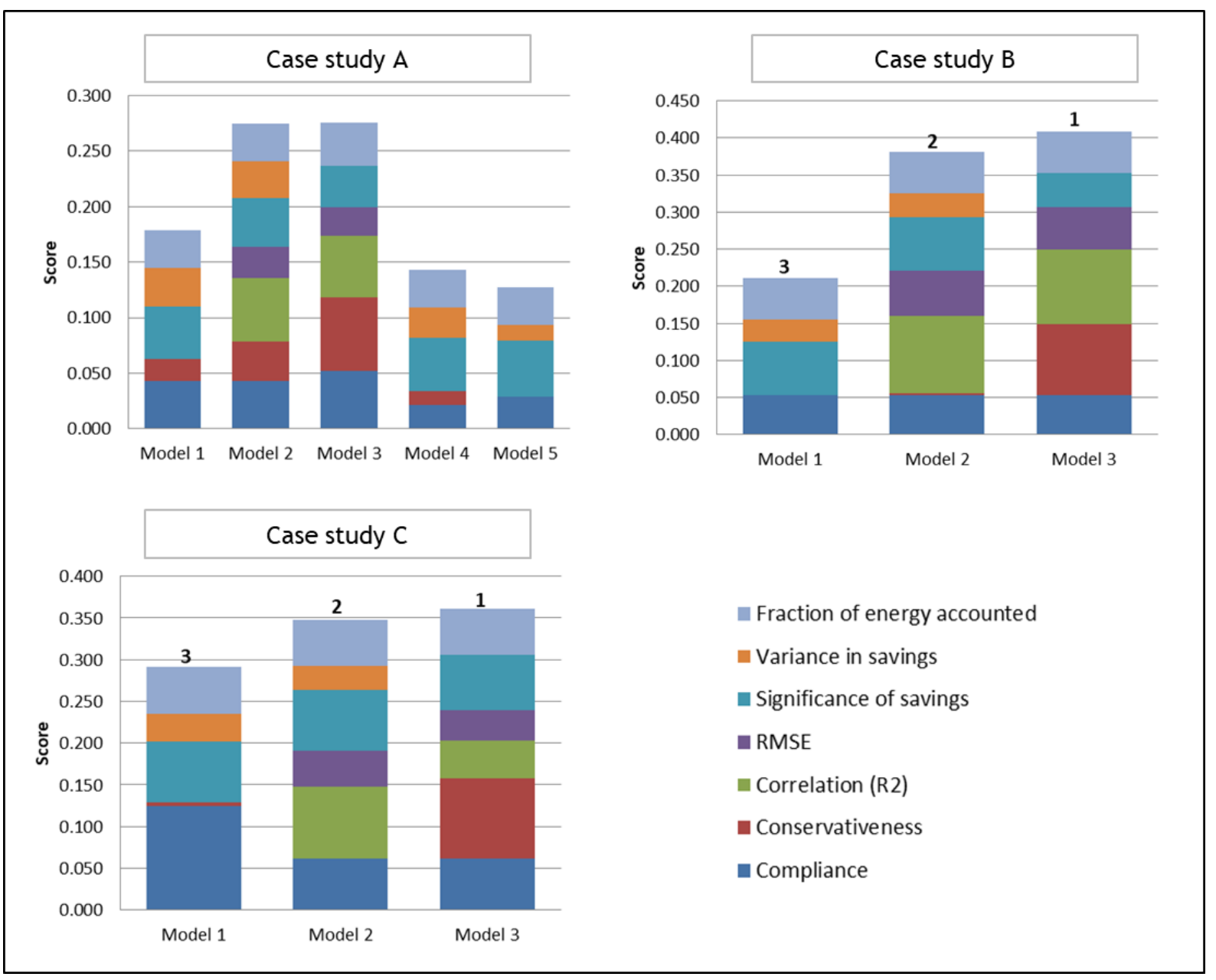

Figure 3: Summary of case study results, indicating the overall scores of each model as well as the contribution of each evaluation criteria to the overall score. 
Model 1 obtained the lowest score for case study $\mathrm{B}$, thus, also the lowest ranking, as shown in Figure 3. This may be attributed to Model 1 having not obtained any score for RMSE and model correlation since Model 1 was based on the unadjusted raw reduction of the compressors energy consumption. Furthermore, Figure 3 shows that Model 1 did not obtain a score for variance in savings because Model 3 was the most conservative model and thus varied the most from the average calculated savings. However, since Model 3 was the most conservative model, a large portion of this model's overall score may be attributed to its conservativeness. Model 3 resulted in the highest overall score and was recommended as the preferred option to model the EE savings of the blast furnace for case study $B$.

Figure 3 shows that for case study $\mathrm{C}$ Model 3 ranked highest, while Model 2 and Model 1 respectively second and third. Although Model 1 was Section 12L-compliant and obtained the largest score with respect to compliance, Model 1 was still outranked by the other two. Model 2 obtained a significant score with respect to model correlation compared with Model 3, but Model 3 obtained a higher overall score. A significant portion of the overall score of Model 3 may be attributed to it being the most conservative model. Model 3 obtained the highest overall score and is thus ranked first, and recommended as the final Section $12 \mathrm{~L}$ model for case study $\mathrm{C}$.

\subsection{Validation of results}

The models recommended by the methodology for each case study were compared with independent SANAS-accredited $\mathrm{M} \& \mathrm{~V}$ results. The comparison for each case study is shown in Table 4. The models selected by the independent $\mathrm{M} \& \mathrm{~V}$ inspection bodies were successful as well as formal Section 12L applications. The model selection process by the independent $\mathrm{M} \& \mathrm{~V}$ inspection bodies was, however, not based on a formal process, but focused on the conservative nature of the selected model as well as model statistics.

Table 4: Comparison of methodology results with independent measurement and verification (M\&V) chosen model.

\begin{tabular}{ccc}
\hline Case study & Methodology & $\begin{array}{c}\text { Independent } \\
\text { M\&V inspec- } \\
\text { tion body }\end{array}$ \\
\hline Case study A & Model 3 & Model 3 \\
Case study B & Model 3 & Model 3 \\
Case study C & Model 3 & Model 3 \\
\hline
\end{tabular}

The results obtained from the methodology are val- idated since they agree with the models recommended by the independent $\mathrm{M} \& \mathrm{~V}$ inspection body. Moreover, the three models selected were comparable to real world applications. Further validation is that Section 12L certificates were issued for all three case studies which were based on the chosen models as shown in Table 4.

\subsection{Discussion}

The various modelling options available to quantify the EE associated with three case studies were evaluated. A final modelling option could objectively be selected by applying the methodology to each case study. The final modelling option obtained the highest ranked score and was therefore considered the most appropriate. The ranked score was obtained by evaluating each modelling option according to the criteria identified from literature (discussed in Section 2.2). The final model, therefore, adhered to all the requirements associated with Section 12L.

The WSM was used to aid in the evaluation and decision-making process. This method was selected for its simplicity and transparency. These were crucial factors to consider since the Section 12L M\&V results needed to be presented to multiple stakeholders that do not necessarily have expertise to understand the more complex methods. Furthermore, the use of a transparent method was critical since there is a significant monetary value associated with Section 12L, so that stakeholders need to be protected.

A more sophisticated and complex decision aid method may, however, be implemented to evaluate accuracy of results and to counter the weaknesses associated with the WSM. A critical weakness of the WSM was to rank alternatives in a way that is heavily conditioned by a criterion if considerably different values were present, e.g., null values. This weakness was highlighted when considering that intensity calculations could not be evaluated according to a coefficient of determination and root mean square error $\left(\mathrm{C}_{3}\right.$ and $\left.\mathrm{C}_{4}\right)$. There are more complex decision aid methods that can be considered to unbiasedly evaluate different calculation methods, e.g., intensity and regression models. The results obtained from this study are, however, still acceptable, since regression analyses are the most prevalent and preferred modelling option in industry (Campbell et al., 2017; Hamer et al., 2017; SABS, 2017).

Table 5 shows the most and least conservative EE savings resulting from the developed modelling options for each of the three case studies. It also shows the respective Section 12L certificate value of ZAR $0.95 / \mathrm{kWh}$ for each of the modelling options. The difference in the Section 12L monetary value from selecting either the most or least conservative modelling option is presented in the last column of Table 5. 
Table 5: Difference in Section 12L certificate value of most and least conservative modelling options.

\begin{tabular}{|c|c|c|c|c|c|c|}
\hline \multirow[t]{3}{*}{ Case study } & \multicolumn{2}{|c|}{$\begin{array}{c}\text { Quantified energy efficiency } \\
\text { savings (GWh) }\end{array}$} & \multicolumn{4}{|c|}{ Section 12L Certificate value (ZAR millions) } \\
\hline & \multirow{2}{*}{$\begin{array}{l}\text { Most conser- } \\
\text { vative }\end{array}$} & \multirow{2}{*}{$\begin{array}{l}\text { Least conser- } \\
\text { vative }\end{array}$} & \multirow{2}{*}{$\begin{array}{l}\text { Most conser- } \\
\text { vative }\end{array}$} & \multirow{2}{*}{$\begin{array}{l}\text { Least conser- } \\
\text { vative }\end{array}$} & \multicolumn{2}{|c|}{ Difference } \\
\hline & & & & & Value & $\%$ \\
\hline A & 251.40 & 341.19 & 238.83 & 324.13 & 85.30 & $26 \%$ \\
\hline B & 234.17 & 348.41 & 222.46 & 330.99 & 108.53 & $33 \%$ \\
\hline $\mathrm{C}$ & 6.17 & 6.84 & 5.86 & 6.50 & 0.64 & $10 \%$ \\
\hline
\end{tabular}

Table 5 shows that the Section $12 \mathrm{~L}$ certificate value could range between $10 \%$ and $33 \%$ if either the most or least conservative modelling option were selected for the three case studies. This is a significant difference and reinforces the need to prove that the most appropriate model was selected objectively.

Previous studies that focused on Section 12L for industries do not provide guidance on how to select a final modelling option between alternative solutions (Campbell et al., 2017; Hamer et al., 2017). The present study aids in the highlighted problem statement by providing a methodology that enables applicants to objectively evaluate alternative modelling options and ultimately select a final modelling option that adheres to all of the Section $12 \mathrm{~L}$ requirements.

The methodology is flexible since the evaluation criteria and criteria weights may be adjusted as desired. It should be noted that the case studies were completed in a retrospective manner, i.e., data for both the baseline and performance assessment was available. It is, however, common practice in industry to generate EE models in a forward-facing manner, based on baseline data only. In such a case, evaluation criteria for the conservativeness of savings $\left(C_{2}\right)$, significance of savings $\left(C_{5}\right)$ and variance of savings $\left(\mathrm{C}_{6}\right)$ will not be applicable.

Different statistical parameters may also be used as evaluation criteria based on the priorities of a specific $\mathrm{M} \& \mathrm{~V}$ application; e.g., adjusted $\mathrm{R}^{2}$ may be considered instead of model correlation $\left(\mathrm{C}_{3}\right)$. This would be suitable when multiple independent variables are used relative to a few data points, i.e., low degree of freedom (Nagappan \& Ball, 2005). The $\mathrm{R}^{2}$ is considered appropriate in the present study since the $\mathrm{M} \& \mathrm{~V}$ case studies are based on single variable models. Further research can be done to determine optimal criteria for different $\mathrm{M} \& \mathrm{~V}$ applications, while also accounting for new developments in the field.

The flexibility of the methodology enables the essence of the methodology to be adapted to various global scenarios that have a direct impact on energy policies. These applications might include alternative $M \& V$ practices (Botes, 2017), renewable energy options (Trotta, 2018), evaluating energy transformation pathways (Volkart et al., 2017), accurate determination of carbon emissions (Talbot \& Boiral, 2013) and energy efficiency options (Chedid \& Ghajar, 2004).

The energy sector has a direct impact on the economic and social development of a region, therefore, an objective and transparent decision-making process (such as the one described in this study) reduces the uncertainty of energy investors and policy makers, which ultimately enables them to build successful energy policies.

\section{Conclusions}

A transparent and objective methodology was devised with the aim to assist Section 12L application processes and to prove that the most appropriate Section 12L energy efficiency model was chosen between multiple options. A financial comparison of the results showed that the monetary value of the Section 12L tax incentive could be influenced between $10 \%$ and $33 \%$ if no method were available to select a final model. The flexibility of the developed method enabled it to be adapted to various global decision-making problems in fields such as renewable energy, carbon tax and various other energy fields that impact energy policies. This approach ultimately produced results that are compliant with the relevant requirements and untainted by personal bias.

\section{Author roles}

Lee-Ann Botes: Responsible for research formulation, data collection and write-up of article.

Walter Booysen: Provided guidance and mentorship throughout the research and write up process.

Marc J. Mathews: Assisted with the write-up of the article. Marius Kleingeld: Financial sponsor that made the research possible. 


\section{References}

Azar, F.S. 2000. Multiattribute Decision-Making: Use of Three Scoring Methods to Compare the Performance of Imaging Techniques for Breast Cancer Detection, Philadelphia: University of Pennsylvania.

Bergh, C. 2012. Energy Efficiency in the South African Crude Oil Refining Industry: Drivers, Barriers and Opportunities, University of Cape Town, South Africa: Masters Dissertation.

Booysen, W. 2014. Measurement and verification of industrial DSM projects, South Africa: PhD Thesis, North-West University.

Botes, L. 2017. Objective evaluation of industrial energy efficiency models for the RSA Section 12L tax incentive, South Africa: Masters Dissertation, North-West University.

Bruen, M. 2008. Systems Analysis - A new paradigm and decision support tools for the water framework directive. Hydrology and Earth System Sciences, 12(2008): 739-749. https://doi.org/10.5194/hess-12-739-2008

Campbell, K. 2016. Evaluating the feasibility of the 12L tax incentive for energy intensive industries, South Africa: Masters Dissertation, North-West University.

Campbell, K., Booysen, W. and Vosloo, J. 2017. Evaluating the feasibility of the 12L tax incentive for energy-intensive industries. South African Journal of Industrial Engineering, 28(3): 15-28. https://doi.org/10.7166/28-3-1836

Carrico, N.J.G, Goncalves, F.V., Covas, D.I.C., do Céu Almeida, M. and Alegre, H. 2014. Multi-criteria analysis for the selection of the best energy efficient option in urban water systems. Procedia Engineering, 7(2014): 292-301. https://doi.org/10.1016/j.proeng.2014.02.033

Chedid, R.B. and Ghajar, R.F., 2004. Assessment of energy efficiency options in the building sector of Lebanon. Energy Policy, 32(2004): 647-655. https://doi.org/10.1016/S0301-4215(02)00328-2

Department of Energy, 2010. Digest of South African Energy Statistics 2009, Pretoria: Energy Information Management, Process Design and Publications. Available online at http://www.energy.gov.za

Du Toit, E.F. 2011. Energy efficiency savings allowance in South Africa: An international comparison, South Africa: Masters Dissertation, University of Pretoria.

Eastman, J.R. 1999. Multi-criteria evaluation and GIS. In: Geographical information systems. New York: Wiley, 493 502.

Efficiency Valuation Organisation, 2012. International Performance Measurement \& Verification Protocol: Concepts and options for determining energy and water savings, Oak Ridge: U.S. Department of Energy.

Gous, A.G.S., Booysen, W. and Hamer, W. 2016. Data quality evaluation for measurement and verification processes. Cape Town, IEEE.

GreenCape, 2015. 12L Income Tax Allowance on Energy Efficiency Savings, Cape Town: GreenCape. Available online at https://greencape.co.za

Grobler, L.J. 2010. International M\&V benchmarks and Eskom practices, South Africa: North-West University.

Hamer, W. 2016. A practical approach to quantify RSA Section 12L EE tax incentives for large industry, South Africa: PhD Thesis, North-West University.

Hamer, W., Booysen, W. and Mathews, E. 2017. A practical approach to managing uncertainty in the measurement and verification of energy efficiency savings. South African Journal of Industrial Engineering, 28(3): 128-146. https://doi.org/10.7166/28-3-1850

Hancerliogullari, G., Hancerliogullari, K.O. and Koksalmis, E. 2017. The use of multi-criteria decision making models in evaluating anasthesia method options in circumcision surgery. BMC Medical Informatics and Decision Making, 17: 14. https://doi.org/10.1186/s12911-017-0409-5

Hasanbeigi, A., Morrow, W., Sathaye, J., Masanet, E. and Xu, T. 2012. Assessment of Energy Efficiency Improvement and $\mathrm{CO}_{2}$ Emission Reduction Potentials in the Iron and Steel Industry in China, Berkeley: Lawrence Berkeley National Laboratory.

Janse van Rensburg, H. M., 2015. Structuring mining data for RSA Section 12L EE tax incentives, South Africa: Masters Dissertation, North-West University.

Kolios, A., Mytilinou, V., Lozano-Minguez, E. and Salonitis, K. 2016. A Comparative Study of Multiple-Criteria Decision-Making Methods under Stochastic Inputs. Energies, 9(566): 21. https://doi.org/10.3390/en9070566

Kolios, A. and Read, G. 2013. A political, economic, social, technology, legal and environmental (PESTLE) Approach for risk identification of the tidal industry in the United Kingdom. Energies, 6(2013): 5023-5045. https://doi.org/10.3390/en6105023

Mateo, J.R.S.C. 2012. Multi Criteria Analysis in the Renewable Energy Industry. Berlin, Germany: Springer Science \& Business Media.

Morrow, W.R., Hasanbeigi, A., Sathaye, J. and Xu, T. 2013. Assessment of Energy Efficiency Improvement and $\mathrm{CO}_{2}$ Emission Reduction Potentials in India's Iron and Steel Industry, Berkeley: Lawrence Berkeley National Laboratory.

Nagappan, N. and Ball, T. 2005. Use of relative code churn measures to predict system defect density. St. Louis, IEEE. https://doi.org/10.1109/ICSE.2005.1553571 
National Treasury, 2013. Regulations in terms of section 12L of the income tax act, 1962, on the allowance for energy efficiency savings, Pretoria: Government Gazette, No. 37136, Government Printing Works. Available online at http://www.energy.gov.za.

Ogryczak, W. 2007. Multicriteria models for fair resource allocation. Control and Cybernetics, 36(2007): 303-32.

Republic of South Africa, 2013. Section 12L of the Income Tax Act (no. 58 of 1962) Deduction in respect of energy efficiency savings, Pretoria: Government Gazette, No. 37019, Government Printing Works. Available online at https://www.greengazette.co.za.

Republic of South Africa, 2015. Taxation Laws Amendment Bill No 29 of 2015, Cape Town: Creda Communications. Available online at http://www.treasury.gov.za.

Saaty, T.L. 2008. Decision making with the analytical hierarchy process. International Journal Services Science, 1(1): 83-98. https://doi.org/10.1504/IJSSCI.2008.017590

SABS, 2017. SANS 50010:2017 Measurement and Verification of energy savings, Pretoria: South African Bureau of Standards.

SANEDI, 2016. Section 12L of the Income Tax Act National Road Show. Midrand, SANEDI. Available online at https://www.sanedi.org.za/12L.html.

Schutte, A.J. 2013. An integrated energy-efficiency strategy for deep-mine ventilation and refrigeration, North-West University, South Africa: Masters Dissertation.

Talbot, D. and Boiral, O. 2013. Can we trust corporates GHG inventories? An investigation among Canada's large final emitters. Energy Policy, 63(2013): 1075-1085. https://doi.org/10.1016/j.enpol.2013.09.054

Triantaphyllou, E. 2013. Multi-criteria Decision Making Methods: A Comparative Study. Berlin, Germany: Springer Science \& Business Media.

Trotta, G., 2018. Factors affecting energy-saving behaviours and energy efficiency investments in British households. Energy Policy, 114(2018): 529-539. https://doi.org/10.1016/j.enpol.2017.12.042

Tzeng, G.H., Lin, C.W. and Opricovic, S. 2005. Multi-criteria analysis of alternative-fuel buses for public transportation. Energy Policy, 33(2005): 1373-1383. https://doi.org/10.1016/j.enpol.2003.12.014

U.S. Department of Energy, 2008. M\&V Guidelines: Measurement and verification for federal energy projects, Washington, DC: US DOE Federal Energy Management Program.

Volkart, K., Weidmann, N., Bauer, C. and Hirschberg, S. 2017. Multi-criteria decision analysis of energy system transformation pathways: A case study for Switzerland. Energy Policy, 106(2017): 155-168. https://doi.org/10.1016/j.enpol.2017.03.026

Worrel, E. and Galitsky, C. 2005. Energy Efficiency Improvement and Cost Saving Opportunities For Petroleum Refineries, Berkeley: Lawrence Berkeley National Laboratory. 